\title{
Optimal operation of heat exchanger networks through energy flow redistribution
}

\author{
Karthika Mohanan ${ }^{1}$ and Sujit Jogwar ${ }^{1}$ \\ ${ }^{1}$ Indian Institute of Technology Bombay
}

December 30, 2021

\begin{abstract}
This paper presents a novel energy flow redistribution methodology to achieve optimal operation of heat exchanger networks (HENs). The proposed method aims to manipulate the propagation path of a disturbance through the network to reduce its impact on utility consumption. Specifically, an optimization problem is formulated to generate new duty targets for heat exchangers of the network when a disturbance is encountered. Subsequently, a feedback control system is designed to track these targets by manipulating bypasses around the process heat exchangers. The effectiveness of the proposed framework is illustrated with the help of three benchmark examples. The proposed approach can handle disturbances in inlet as well as target temperature, inlet flow and heat transfer coefficient of individual heat exchangers.
\end{abstract}

\section{Hosted file}

BR_submit.pdf available at https://authorea.com/users/453267/articles/551162-optimaloperation-of-heat-exchanger-networks-through-energy-flow-redistribution 